\title{
Assessment of the level of Knowledge of Pediatric Staff towards Principles of Principles of Infection Control at Selected Units, Saudi Arabia
}

\author{
Dr. Mohammed Hussain Sisi ${ }^{1}$, Dr. Ahmed Alattas ${ }^{2}$ \\ ${ }^{1,2}$ Pediatric Resident, Maternity and Children Hospital, Almadina Almonwarra ,Saudi Arabia
}

\begin{abstract}
Background: Pediatric professionals are the most numerous contingent among health professionals and provide direct care to patients, making them vulnerable to the risks of biological exposure during medical practice. Hazardous situations of exposure to biological material, control measures related to Hospital Acquired Infections (HAIs) and adherence to standard precautions (SP) are well defined for general hospitals and other health services, but in the search for studies on this topic in mental health services, no research was found. (Smyser, Bryce \& Joseph, 2009). Objective: The current research aims at assessment of the level of knowledge of pediatric staff towards principles of Principles of Infection Control at selected units, Saudi Arabia. Method: The descriptive research design was conducted at the Selected Pediatric Units -Saudi Arabia. . Tool was consists of 22 items self-administered questionnaire was provided to 100 Pediatric Units in the research setting based on their area of their specialties to assess their level of level of knowledge of pediatric staff towards principles of Principles of Infection Control at selected units, Saudi Arabia. Results: The results of the current study showed the level of knowledge of Pediatric Staff about Principles of Infection Control was significantly associated with many variables (Table.1). Furthermore, the findings of the current study showed the majority (91.0\%)* of the respondents were very aware of Principles of Infection Control with statistically significantly difference in relation to the aspect of principles of infection control. Moreover, it was found that Surgical staff' had high level of knowledge (89.3\%)* in relation to pediatric staff is accountable for ensuring their adherence, which reflect that they are adequately trained and competent to perform their role towards utilization of Principles of Infection Control. Furthermore, majority of the participants (92.5\%)* are responsible for supporting that systems of compliance towards Principles of Infection Control. Conclusions: The current study results revealed that there were a high levels of Knowledge among Pediatric Staff towards' Principles of Infection Control within the study setting.
\end{abstract}

Keywords: Health Care Providers; Attentiveness \& Principles of Infection Control

\section{Introduction}

While professionals spotlight their attention on the mental health of patients, often conducting clinical procedures involving biological fluid and sharp material, making it compulsory. The unexpected situations that arise during patient care in psychological distress intensify the risk of occupational exposure, as these can become agitated, leading to performing procedures in an improvised way with incorrect technique or without the use of suitable Personal Protective Equipment (PPE).

The set of measures to put a stop to infection which should be adopted by professionals in assisting all patients, regardless of suspected or confirmed infection status, and in any environment where health care is utilized. (Eustis, Wright, Fowlie \& Slovis, 2007).

According to Christian, et al., (2004) , mentioned that , pediatric staff' is more required of acquiring Principles of Infection Control through personal exposure to infectious diseases as they are dealing with vulnerable group with low immunity level. The minority studies have reported on surgical staff adherence towards Personnel Protective Equipments and reported lack of adequate practices in relation to compliance towards the personnel protective equipments.

Exposure to health hazards are expected to influence definite high-risk for all the health care providers. All the health care workers especially the Pediatric Units who are working in Pediatric Unit sand Operation Theater are more required to have a reason of a better understanding in adherence with PPE usage which is significant as it provides an assessment of the efficacy of assemble preventative strategies. This could then (SSI) at to recognize the preventive variables which are likely to improve the compliance and decrease the risk of Principles of Infection Control. Then, it is able to integrate these preventative approaches into the strategies of health care setting. (Loeb, et al., 2004 \& Ofner, et al., 2003)

A principle of Infection Control is the only approach so that all these Principles of Infection Controls could be prevented. Inadequate experience of Pediatric Units in performing invasive procedures, they are at particular risk of exposure to blood-borne pathogens (Chopra, et al., 2008). Surgical staff' should have reasonable Attentiveness and performance in relation to adherence to personnel protective equipments. Additionally, Low \& McGeer (2003), reported that dedicated training must be conducted before a Pediatric Unitscaring for any patient procedure particularly the ones concerning sharp devices. Physicians' compliance towards the Principles of Infection Control has been reported to be with low rate. (Spring, 2007).

Hazards caused by non adherence to Principles of Infection Control by the health care providers, statistics reported by the Central Register of Occupational Diseases in Poland indicates that among 314 new cases of occupational diseases in HCWs in 2005, HBV and HCV represented $42.6 \%$ of all

\section{Volume 6 Issue 12, December 2017}




\section{International Journal of Science and Research (IJSR) \\ ISSN (Online): 2319-7064}

Index Copernicus Value (2013): 6.14 | Impact Factor (2015): 6.391

cases.9 Despite the substantial reduction in HBV Principles of Infection Control since vaccination was introduced in 1989, the incidence of HCV hepatitis in Poland is still on the increase in this occupational group. . Chaovavanich, et al., (2004) \& Siegel, et al., (2007).

Principles of Infection Control consciousness education has not been prominent among health care workers especially the category of surgical staff, particularly in developing countries. To the best of our Attentiveness and standardized practices with PPE among surgical staff. We, therefore, conducted this study to assess the levels of Attentiveness towards Principles of Infection Control among Pediatric Units during their duties at the selected pediatric units, Saudi Arabia.

\section{Participants and Methods}

The participants were selected from Surgical Units. After signing an informed written consent form, the questionnaire was given to each participant. Before administration of the questionnaire, the purpose of the study was explained to each respondent and confidentiality of the information assured.

The research was carried out the authors who were appropriately trained in administering the informed consent and the self-report questionnaire to the health care workers. In this cross-sectional study, a structured questionnaire prepared by the authors, was administered to the participants. 16-itemes self-administered structured questionnaire about Attentiveness of Pediatric Staff about Principles of Infection Control in the health care system was devised de novo and tested. It included a full range of response options, designed to identify the dental restoratives' level of knowledge Pediatric Staff towards Principles of Infection Control in the selected setting. Prior to distribution of the questionnaire, a pilot study was done on a selective group of health care workers who were asked to fill out the questionnaire and return it back with their comments and criticism. Minor changes were then made to the final instrument.

The initial part of the questionnaire consisted of demographic information such as occupation, age, gender, and the marital status. The second part of the questionnaire comprised of questions regarding their Attentiveness dental restoratives' level of knowledge Pediatric Staff towards Principles of Infection Control in the selected setting.. This part also assessed Attentiveness of policies regarding universal precautions, availability of protective equipments and measures how they value the use of protective equipments. It took approximately 15 minutes to complete each questionnaire.

The level of aware towards Principles of Infection Control by examining questions about: use of protective barriers such as gloves and gown, mask and protective goggles. A score of "1" was (SSI) for a correct answer and "0" for an incorrect answer. A health care worker who obtained a total score of "5" was considered "very Attentive able," "4 or 3" "somewhat Attentive;" and "1 or 0" "not Attentive able."

The Principles of Infection Control enquired by the health care worker include N95 mask, surgical mask, paper mask, protective goggles, gowns, gloves, and (SSI)r cover, among other equipments. These vary depending on the duty performed by the health care provider. If less than half of the personal protective equipment identified by the particular health care worker was provided, then provision was considered "inadequate." If more than half of the protective equipment identified by the participants was provided, then provision was considered "adequate."

The data were coded and analyzed by SPSS ${ }^{\circledR}$ for Windows ${ }^{\circledR}$ ver. 12.0. Strict confidentiality was maintained. All the data were stored in computers at a secured location, with access provided only to the researchers involved in the study. The $\chi^{2}$ test was used to test association between categorical variables. A $\mathrm{p}$ value $<0.05$ (two-tailed) was considered statistically significant

\section{Results}

Table 1: Percentage of the Level of knowledge of Pediatric Staff about Principles of Infection Control at Selected Surgical Units, Saudi Arabia

Level of knowledge of Pediatric Staff at Pediatric Units about Principles of Infection Control Variables (\%)

\begin{tabular}{|l|c|c|c}
\hline Level of knowledge of Pediatric Staff about Principles of Infection Control & $\begin{array}{c}\text { Not } \\
\text { Aware }\end{array}$ & $\begin{array}{c}\text { Somewhat } \\
\text { Aware }\end{array}$ & $\begin{array}{c}\text { Very } \\
\text { Aware }\end{array}$
\end{tabular}

Senior management is responsible for ensuring that the healthcare system supports an Principles of Infection Control prevention and control (IPC) program that effectively prevents healthcare-associated Principles of Infection Controls (I C)and the transmission of (SSI) of epidemiologically important pathogens

Senior management is accountable for ensuring that an adequate number of trained

personnel to avoid (SSI) to the IPC program and adequate Staff in other departments that play a key role in (SSI) prevention (eg, environmental services)

Personnel from the IPC program, the laboratory, and information technology departments are responsible for ensuring that systems are in place to support the surveillance program of utilization of Principles of Infection Control

PC leadership is responsible for ensuring that an active program to identify (SSI)s is implemented, that (SSI) data are analyzed and regularly provided to those who can use the information to improve the quality of care (eg, unit staff, clinicians, and hospital administrators), and that evidence-based practices are incorporated into the program

Senior and unit leaders are accountable for ensuring that appropriate training and

Volume 6 Issue 12, December 2017

www.ijsr.net

Licensed Under Creative Commons Attribution CC BY 


\section{International Journal of Science and Research (IJSR) \\ ISSN (Online): 2319-7064}

Index Copernicus Value (2013): 6.14 | Impact Factor (2015): 6.391

\begin{tabular}{|c|c|c|c|}
\hline $\begin{array}{l}\text { Senior management is accountable for ensuring that pediatric staff, including licensed and } \\
\text { no licensed personnel, are adequately trained and competent to perform their job } \\
\text { responsibilities towards Principles of Infection Control }\end{array}$ & $5(5.0 \%)$ & $10(10.0 \%)$ & $85(85.5 \%)^{*}$ \\
\hline Adequate information about how to apply Principles of Infection Control & $0(0.5 \%)$ & $1(0.7 \%)$ & $99(98.3 \%) *$ \\
\hline
\end{tabular}

The level of knowledge of Pediatric Staff about Principles of Infection Control was significantly associated with many variables (Table .1).

The results of the current study showed the level of knowledge of Pediatric Staff about Principles of Infection Control was significantly associated with many variables (Table .1). Furthermore, the findings of the current study showed the majority $(91.0 \%) *$ of the respondents were very aware of Principles of Infection Control with statistically significantly difference in relation to the aspect of principles of infection control. Moreover, it was found that Surgical staff' had high level of knowledge $(89.3 \%)^{*}$ in relation to pediatric staff is accountable for ensuring their adherence, which reflect that they are adequately trained and competent to perform their role towards utilization of Principles of Infection Control. Furthermore, majority of the participants $(92.5 \%)^{*}$ are responsible for supporting that systems of compliance towards Principles of Infection Control.

\section{Discussion}

There was little evidence that poor compliance rates were associated with the unavoidable difficulty of performing invasive procedures in small patients. Specifically, compliance had no apparent relationship to patient age, as would be expected if the principal barrier to universal precautions were the intrinsic difficulty in performing procedures on small subjects. Moreover, compliance with universal precautions was not influenced by the apparent difficulty of the procedure, as reflected by the number of attempts required for its completion.

This self-reported adherence rate likely overestimates actual adherence. Henry et al, (2012) demonstrated that point estimates of self-reported adherence with all barrier precautions with the exception of gloves. Furthermore, the current study findings is consistent with the reported results of the study carried out by, O'Boyle et al.,(2011) found that the correlation between reported and observed adherence with hand-washing recommendations among dentists was quite low $(\mathrm{r}-.22)$. To overcome this overestimation, respondent reports regarding their colleagues' adherence with expected practices have been used as a surrogate measure for actual adherence .toward PPE. Using this measure, we would estimate that adherence in our study is approximately $47 \%$. The fact that $(80 \%)$ of respondents felt they could improve their use of PPE confirms that they were aware that their adherence is suboptimal.

The results of the current study showed the level of knowledge of Pediatric Staff about Principles of
Infection Control was significantly associated with many variables (Table .1). Furthermore, the findings of the current study showed the majority $(91.0 \%) *$ of the respondents were very aware of Principles of Infection Control with statistically significantly difference in relation to the aspect of principles of infection control. Moreover, it was found that Surgical staff' had high level of knowledge $(89.3 \%) *$ in relation to pediatric staff is accountable for ensuring their adherence, which reflect that they are adequately trained and competent to perform their role towards utilization of Principles of Infection Control. Furthermore, majority of the participants $(92.5 \%) *$ are responsible for supporting that systems of compliance towards Principles of Infection Control.

Little is known about how HCWs are currently using recommended barrier precautions to prevent spread of influenza and other respiratory viruses, or the factors that influence adherence. Identified influences on adherence to best practice guidelines have included Attentiveness, attitude, belief, and behavioral factors Predictors of PPE use Attentiveness ' of correct PPE, age, and race were not significantly associated with reported PPE adherence in simple logistic as showed in (Table 1). Pediatric Units role, marital status, and specific beliefs about PPE use and efficacy were found to be significant predictors of high levels of adherence with PPE in both simple and multivariable logistic on analyses.

Majority of respondents reported a belief that PPE use would protect them and their patients, respectively, from getting influenza. Although this belief is plausible, given Centers for Disease Control and Prevention recommendations for PPE use, as we have mentioned, it is not supported by evidence from randomized clinical trials. Further, neither did this belief seem to influence behavior nor did it translate to similarly high levels of Attentiveness regarding recommendations. In fact, a large proportion of our respondents also demonstrated important Attentiveness gaps. This current study findings $s$ congruent with the results carried out by Sandrock \& Stollenwerk (2008), who reported that, more than $75 \%$ of respondents were unable to identify the group of precautions expected to confer appropriate protection from Principles of Infection Control. This Attentiveness gap suggests that some dentists may be unaware that they are inadequately protecting themselves and their patients. At least half of our respondents reported that complying with recommended PPE was inconvenient. Inconvenience, in turn, was predictive of poorer adherence.

\section{Acknowledgment}

Appreciation is hereby extended to all the participants

Volume 6 Issue 12, December 2017 


\section{International Journal of Science and Research (IJSR) \\ ISSN (Online): 2319-7064}

Index Copernicus Value (2013): 6.14 $\mid$ Impact Factor (2015): 6.391

Conflicts of Interest: None declared.

\section{References}

[1] Eustis TCWright SWWren KDFowlie EJSlovis CM , Compliance with recommendations for universal precautions among prehospital providers. Ann Emerg Med. 2008 ;25512- 515.

[2] Smyser MSBryce JJoseph JG AIDS-related knowledge, attitudes, and precautionary behaviors among emergency medical professionals. Public Health Rep. 2009;105496- 504.

[3] Schwartz RJJacobs LMJuda R Evaluating the compliance of universal precautions before and after an educational seminar on infectious diseases. Conn Med. 1992;563- 57.

[4] Henry KCampbell SMaki M A comparison of observed and self-reported compliance with universal precautions among emergency department personnel at a Minnesota public teaching hospital: implications for assessing infection control programs. Ann Emerg Med. 1992;21940- 946

[5] Talan DABaraff LJ Effect of education and the use of universal precautions in a university hospital emergency department. Ann Emerg Med. 1990;191322- 1326.

[6] Baraff LJTalan DA Compliance with universal precaution in a university hospital emergency department. Ann Emerg Med. 1989;18654- 657.

[7] Orji EO, Fasubaa OB, Onwudiegwu U, Hutin Z. Occupational health hazards among health care workers in an obstetrics and gynaecology unit of a Nigerian teaching hospital. J Obstet Gynaecol 2002;22(1):758.Accessed June 17, 2007

[8] Low DE, McGeer A: SARS - One year later. N Engl J Med 2003; 349:2381-2382.

[9] Chaovavanich A, Wongsawat J, Dowell SF, et al: Early containment of severe acute respiratory syndrome (SARS); experience from Bamrasnaradura Institute, T(SSI)land. J Med Assoc T(SSI) 2004; 87:1182-1187.

[10] Booth TF, Kournikakis B, Bastien N, et al: Detection of airborne severe acute respiratory syndrome(SARS)corona-virus and environmental contamination in SARS outbreak units. J Infect Dis 2005; 191:1472-1477.

[11] Cabana MD, Rand CS, Powe NR, et al: Why don't physicians follow clinical practice guidelines? A framework for improvement. JAMA 1999; 282:14581465

[12] Siegel JD, Rhinehart E, Jackson M, et al; Healthcare Principles of Infection Control Control Practices Advisory Committee. 2007 Guideline for Isolation Precautions.

[13] Pittet D, Simon A, Hugonnet S, et al: Hand hygiene among physicians: Performance, beliefs,and perceptions. Ann Intern Med 2004; 141:1-8.

[14] O'Boyle CA, Henly SJ, Larson E: Understanding adherence to hand hygiene recommendations: The theory of planned behavior. Am J Infect Control 2001; 29:352-360.
[15] Sax H, Uckay I, Richet H, et al: Determinants of good adherence to hand hygiene among healthcare workers who have extensive exposure to hand hygiene campaigns. Infect Control Hosp Epidemiol 2007; 28:1267-1274.

[16] Berhe M, Edmond MB, Bearman GM: Practices and an assessment of healthcare workers' perceptions of compliance with Principles of Infection Control control awarness of nosocomial Principles of Infection Controls. Am J Infect Control 2005; 33:55-57.

[17] Hamilton LC: Statistics with Stata, updated for version 9. Belmont, Thomson-Brooks/ Cole, 2006.

[18] Kollef MH. Ventilator-associated pneumonia. A multivariate analysis. JAMA. 1993;270:1965-70. [PubMed].

[19] Kollef MH. The identification of ICU-specific outcome predictors: a comparison of Prothotodontic, Prothotodontic, and cardiothoracic ICUs from a single institCDon. Heart Lung. 1995;24:60-6. [PubMed]. 